\title{
Communicating with prostate cancer patients: Psychosocial profile and determinants of seeking psychosocial care
}

\author{
Laura Daeter $^{1 *}$, Adriaan Visser ${ }^{2}$, Chantal van Harten ${ }^{3}$ and Bert Voerman ${ }^{4}$ \\ ${ }^{1}$ Faculty of Clinical Health Sciences, Department of Nursing Science, University Utrecht, The Netherlands \\ ${ }^{2}$ Research Center Innovations in Care, Rotterdam University of Applied Sciences, The Netherlands \\ ${ }^{3}$ Patiëntenfederatie NPCF, The Netherlands \\ ${ }^{4}$ SPEL Almere, The Netherlands
}

\begin{abstract}
Prostate cancer patients often express needs for supportive care, eventhough they are not frequently participating in supportive care activities. We studied the psychosocial care needs in relation with the intention seeking psychosocial care in order to improve the communication with the prostate cancer patients about the best fitting psychosocial care. In a cross-sectional study a convenience sample of patients completed the Supportive Care Needs Survey (SCNS), patient's attitude towards psychosocial care seeking, perceived social support and self-efficacy (using the ASE model), distress was measured by the HADS, the former use and evaluation of supportive care, and several background factors (age, SES, marital status, co-morbidities, disease stage).

We included 87 patients, who returned the questionnaire. More than one third of all men did look for expert information. We found significant associations between the behavioral intention of supportive care use and: age, attitude, needs, and the factors distress previous experience with and evaluation of supportive care. Multiple regression analysis pointed out that experiencing psychological and physical needs and depression are the main determinants of the intention to use supportive care. Path-analysis showed that age, marital status and co-morbidity influencing through physical and psychosocial needs, are external factors in the model of explaining the intention to supportive care use. Psychological needs, physical needs and depression are important determinants of the intention to supportive care use. Urologists and urology/oncology nurses and other health-care professionals may use the results for patient centered referrals and the development of more tailormade psychosocial interventions.
\end{abstract}

\section{Introduction}

Incidence figures indicate that more than 10.000 Dutch men suffer from prostate cancer in 2012 (PCA) [1,2]. Symptoms like urinary dysfunction and impotence are becoming more manifest in the advanced stages of the disease, expanding men's psychosocial problems [3,4]. Although patients may look for supportive care in order to cope with problems, facilities aren't used very frequently or, given patient's specific problems, aren't appreciated. Clarification of the factors that influence men with prostate cancer patients' intention to seek psychosocial care facilities is important for the development of tailor-made psychosocial care.

Patient's problems: Uncertainty about prognosis and treatment related side effects, often lead to physical, emotional, psychosocial problems, which may develop into feelings of distress in almost $35 \%$ of all PCA patients [4]. Besides general cancer related problems (e.g. pain, fatigue) also specific problems like erectile dysfunction, incontinence, urinary and intestinal problems during the first years after treatment are reported [4,5-8], causing too physical distress, as well as psychological and social problems [9-13].

Voerman et al. found traumatic stress in one third of the PCA patients. Disease stage, treatment and social economic status (SES) cohered with these stress reactions [14]. In a five year follow up study on anxiety and depression after PCA diagnosis and treatment Korfage et al. reported that of all patients experiencing high anxiety, prostatectomy patients reported better mental health, less anxiety and feelings of depression than men treated with radiotherapy. Also age seemed to correlate with anxiety and depression since radiotherapy patients were older. Based on their results they recommend early detection of patients at risk for anxiety and depression after their diagnosis [15]. Bloch et al. reviewed the literature on PCA patient's psychological adjustment, published between 1994 and 2006. Based on longitudinal studies, they concluded that early signs of distress indicate a poor future psychological adjustment [16].

Supportive care needs: According to Sanson-Fisher et al. cancer patients experience needs for support particularly in the psychological, healthcare system and informational as well as the daily living domain [17]. Also disease stage and age were associated with patient's needs. Patients in remission experienced fewer needs. And higher age cohered

Correspondence to: Laura Daeter. MSc., Faculty of Clinical Health Sciences, Department of Nursing Science, University Utrecht, Goudenregenlaan 12, 1214 ND Hilversum, The Netherlands, Tel: +31 652074787; E-mail: robin.laura@kpnplanet.nl

Key words: prostate cancer, intention to seek supportive care-use, supportive needs, ASE factors, distress

Received: August 28, 2015; Accepted: September 16, 2015; Published: September 21, 2015 
with lower levels of unmet needs. Bisson et al. found relatively low levels of psychopathology in early-diagnosed PCA patients [18]. Their group emphasized the need of clear guidelines to detect and support PCA patients with mental health problems. Smith et al. [19] concluded that more attention should be given to sexual and psychological needs, especially for younger men with lower education having surgery. Chamber et al. [20] reviewed the literature on interventions to improve patient's adjustment. They appoint the urgent need for specific attention and interventions for advanced patients, whereas Hinz et al. [21] concluded in their study on degree and course of psychological distress that most PCA patients don't need help from mental health professionals. These different results seem inconclusive about severity and prevalence of psychosocial problems, their relation to age and disease stage, and the needed psychosocial interventions, for men suffering from prostate cancer.

Use of supportive care facilities: Voerman et al. discussed factors influencing patient's use of supportive care facilities. Their study applied the attitude, the perceived social support and the efficacy (ASE)-model) to explain variation in the use of support care facilities. They found significant correlations between supportive care seeking behavior and (lower) age, (higher) social-economic status (SES), lack of social support and a positive attitude towards participation [22]. They found that self-efficacy was a more powerful predictor of supportive care use than attitude, (lack of) social support, age and SES. Corboy et al. concluded that attitudes towards support services are predictive for the actual psychosocial care use [23]. With regard to the type of support, other studies emphasize the importance of a more individualized approach to help adequately men to address thoughts and feelings after PCA diagnosis, also including a more gender adapted approach [24,25]. This individualized and more tailor-made approach is supported by the results of Carter et al. who found that men search for information and support in order to be able to do their relevant activities [26]. This aligns with Sanson-Fisher's and Bisson's conclusion that standard care should consist of adequate support as well as information supply $[17,18]$.

Not fitting supportive care use: In spite of the problems PCA patients express and the available support facilities, studies point to a limited use of supportive care interventions [27]. At the same time facilities are sometimes not widely available either [9]. Dutch centers for psychosocial oncological supportive care also observe this phenomenon [28,29]. Voerman et al. describe in a 2002 review seven intervention studies. Emotional support seems to be of minor importance to PCA patients. In general, men prefer information about the disease and treatment in a formal setting with expert speakers focusing on information and education. Information packages, telephone interventions and interventions alternating recreation activities with discussion sessions were well received. The effect of interventions on anxiety and distress was limited and studies were small and had design limitations [9]. Since 2002, 12 new intervention studies were published. Due to ineffective interventions, organizational problems as well as contradictory study results, their impact seemed rather limited [30-33]. Patient information is found to be successful at improving knowledge, quality of life and care satisfaction, especially when combined with a discussion group [33-36], however much of the used PCA educational material omitted important information or was incorrect [37].

Both the lack of fitting and effective supportive care interventions and the increasing incidence of PCA with related psychosocial problems, emphasize the need for interventions which address patient's needs.

Research questions: Despite increasing incidence and risk of possible decline in psychosocial wellbeing, patients make limited use of psychosocial support eventhough they express a need for information $[27,28,37]$. This requires further research into needs of PCA patients and the influence of these needs on the intention to seek care. This will help to address the development of psychosocial care interventions that are based on PCA patient's needs. Such needs based interventions may also contribute to improve patient referrals by urologists and urology nurses.

In this study we intend to appoint determinants of the intention to seek supportive care. We aim to understand PCA patient's psychosocialsupport care seeking behavior by using the theoretical model as presented in Figure $1[38,39]$. With the Supportive Care Needs Survey (SCNS) we assessed the needs in relation to psychosocial and cancer specific physical problems [40,41]. Further, we hypothesized that attitudes towards psychosocial care, the perceived supportive social environment, and positively estimated self-efficacy towards finding support (ASE-model), may influence the intention to seek psychosocial care facilities. Based on this model, we also studied the influence of the so called external factors in this model: biographical and medical factors, distress and former experience with supportive care (Figure 1). The core studied research questions are:

1. What are the needs of men, suffering from of PC for psychosocial support, their attitude towards psychosocial care, their perceived social support, their estimated self-efficacy towards finding support, their distress and the former experience with supportive care?

2. How strong is the intention of men suffering from of PC to use psychosocial

\section{support facilities?}

3. Do the psychosocial care needs, the ASE factors, the distress, the former use and evaluation of psychosocial care facilities, and background factors influence the intention to use psycho-social care facilities?

\section{Methods}

\section{Ethical considerations}

This study was presented to the Central Committee on Research Involving Human Subjects and was approved. Patients gave their informed consent to study participation by contacting the investigators and returning the filled out questionnaires [38].

\section{Design}

In a cross-sectional design we asked 87 prostate cancer patients to fill out a self-administered hardcopy or a digital questionnaire $[38,39]$.

\section{Participants}

We recruited prostate cancer patients resident in the Netherlands' southwest region, corresponding with the working area of the Vruchtenburg, a foundation for psychosocial oncology, who intended to extend their service to PCA patients. Inclusion criteria were: patients with a clinical prostate cancer diagnosis and already had or were going to have treatment. Patients were eligible if they could read and write in Dutch. Patients received an information letter through their urologist, urology-oncology nurse, patient organization, 


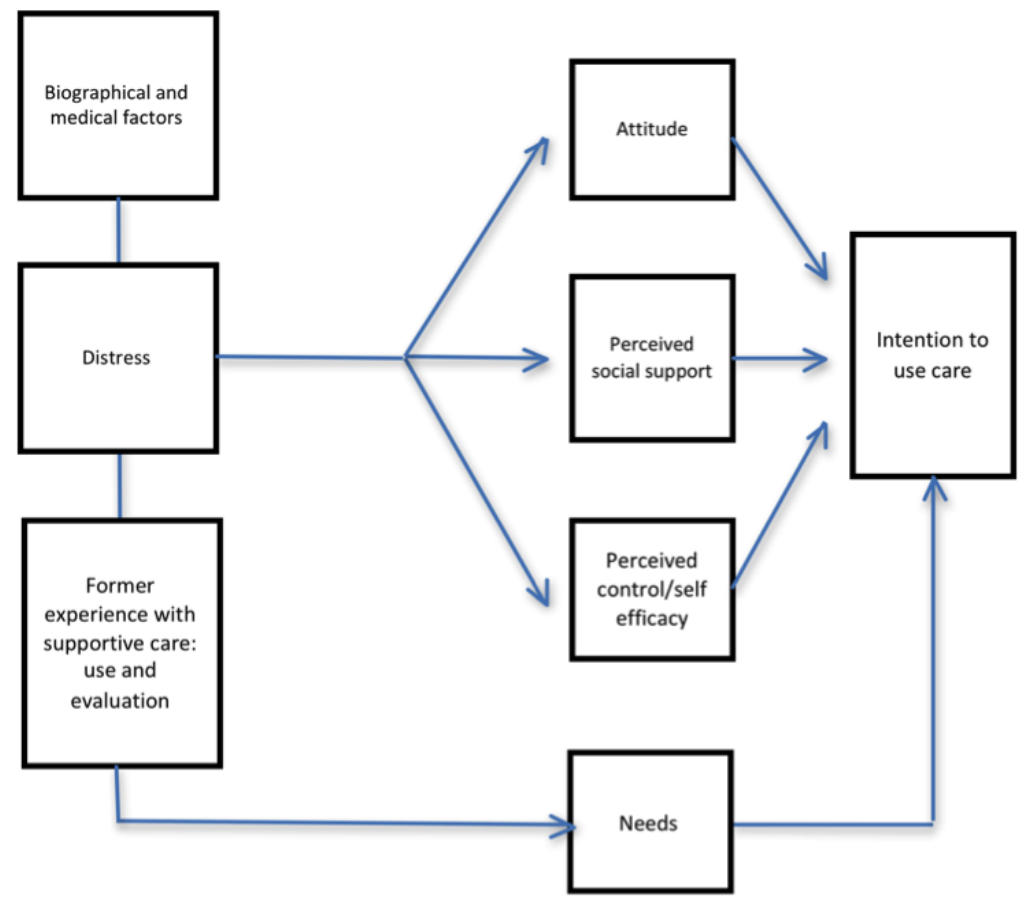

Figure 1. The model for studying seeking supportive care based on Voerman et al. [14] and Segaar et al. [45].

psycho-social therapeutic center, or the research coordinator (LD). Study announcements were published both in local and in national newspapers. The Dutch Prostate Cancer Patient Foundation (PKS) published a study announcement at their website and in their magazine. If patients consented to participate, they could get in contact with the research coordinator (LD) by telephone or email. Patients were recruited between March and April 2012.

\section{Measures}

Supportive care seeking is composed of a general question about looking for support (answers yes or no). This is combined with a question about finding specific support facilities such as telephonic support, individual counseling, general disease information, fellow patients support groups or support from an institute for psychosocial care (answers yes, no). We also asked about men's intention to use a form of supportive care (four-point Likert-scale; certainly no intention - most certainly going to). The total score of these three questions is defined as the intention of supportive care seeking.

Patient's needs were assessed with the Supportive Care Needs Survey (SCNS). This validated Australian study parameter describes needs and problems across five domains: daily living/physical activity; psychological functioning; patient care and support; sexuality; informational and healthcare system issues [40,41]. We received the authors' permission to use this scale. The SCNS was translated in Dutch according to the backward selection method and was previously used in a study on care needs in breast cancer patients [42]. Needs are measured on a five-point scale. Phrasing of items was adjusted to the general Dutch language practice.

The measurement of the ASE variables was adopted from a previous study on the application of the Attitude Social support and Efficacy (ASE) model [14]. The attitudes about seeking psychosocial care were measured with (1) the sum score of a combination of four questions on the expected gain to talk about the disease and personal problems, and (2) the importance to do so, e.g. expecting to obtain new ways to learn how to cope with PCA, and to find new disease related information. The multiplied attitude values vary from -2 to +2 . High positive, scores stand for present beliefs $(>0)$, which are evaluated as very important to the participant (values +1 and +2 ). The perceived social support (S) was measured by the expected and importance of support by the partner, the medical specialist and significant others. Self-efficacy (E) was measured by three questions about available time, energy and perceived possibilities to participate in supportive care sessions [43].

Following the ASE model, also so-called external factors were studied: biographical factors (education, income and work level; age and marital status) and medical characteristics (treatment, metastasis and co-morbidity). To assess distress as external factor, we used the Hospital Anxiety and Depression Scale (HADS) as a general measure of anxiety and depression [15,21,44].We also included as external factor the experience with as well as the evaluation of former used psychosocial care interventions [22,45-47].

\section{Statistical analysis}

Using SPSS 18.0, descriptive statistics were applied for the sample characteristics. Cronbach's alpha was determined for all scales [48]. With Pearson's correlation coefficients the strength of the relationship was measured between the intention to seek support and needs, ASE-factors, the external biographical and medical factors, and the former use and evaluation of received care [48]. We applied a multiple regression analysis according to the forward selection method, based on the significant correlations between intention and the applied other factors at $\mathrm{p} \leq .05$ [44]. A multinominal logit regression and backward selection method were applied during a path-analysis, in order to assess 
the statistically significant paths $(\mathrm{p} \leq .05)$ and their corresponding magnitude according to the pseudo R-square of Nagelkerke [49].

\section{Results}

\section{Response}

The 87 patients who responded were recruited by a announcement via urologists and other healthcare professionals (20\%), (social) media (17\%), and patient organization's announcement (53\%). Patients were also recruited via the psychosocial therapeutic centre's website (10\%). Because patients were not requested directly by the researcher (LD), the number of invited men could not be identified. All 87 patients, consenting to participate by approaching the investigators, returned a hardcopy or digital questionnaire.

\section{Reliability of the measurement scales}

Table 1 contains information about the reliability of all used measurement scales. Inter-item correlations were performed in case of scales with two items. Perceived social support is composed of three separate items because the inter-item correlations were too low. All other scales showed an acceptable reliability (Table 1).

\section{Socio-demographic characteristics}

Respondents were between 44 and 84 years, with mean age 66,4 years (Table 2). Most participants were married or having a relationship (91\%), were higher educated (49\%) and worked in the field of (higher) management or as academic professionals (48\%) with a monthly salary between 2300 to 4800 euro's (61\%). Almost $60 \%$ of the participants in the sample have a midrange to high SES-score. Further, half of the men live in the southwest of the Netherlands, due to the sampling procedure.

\section{Medical characteristics}

There is variation in the time since diagnosis and treatment. Two participants mentioned diagnosis and treatment up to 20 years ago. Almost half of the men have had surgery and 56\% have had either internal or external radiation therapy (Table 2). All known therapies were reported; a few men also used acupuncture and homeopathy or other alternative therapies.

\section{Supportive care needs}

Supportive care needs were experienced in all six areas: physical, psychological, sexual, healthcare system-related, and care and support related (Table 3). A value zero-score means that the item was not applicable to the patient's situation; the score one indicated that existing problems were solved; score two to four means that participants experience increasing needs. Psychological needs were expressed by $80 \%$ of the participants. Patients also expressed needs for support concerning the healthcare system (77\%), sexual issues (73\%) and care and support (70\%); $69 \%$ of the study participants expressed physical needs for support. Less than half of the respondents (44\%) experienced needs concerning incontinence, however for $41 \%$ of the respondents this was an issue in the past, and is presently resolved.

\section{Attitude, perceived social support and efficacy}

Respondents mainly hold positive beliefs regarding care seeking and value these beliefs as important to them, appreciated by $83 \%$ of the study participants. A low negative score $(<0)$ either means that subjects consider the beliefs phrased in the statements regarding supportive

Table 1. Measurements and scale values $(\mathrm{N}=87)$.

\begin{tabular}{|c|c|c|c|c|}
\hline Instruments & Number of items for sumscore & Theoretical range & Mean (SD) & Reliability \\
\hline \multicolumn{5}{|l|}{ SCNS } \\
\hline Physical & 5 & $5-23$ & $5,80(4.9)$ & 0.79 \\
\hline Psychological & 10 & $10-48$ & $17.3(10.6)$ & 0.9 \\
\hline Sexuality & 4 & $4-20$ & $7.7(5.4)$ & 0.93 \\
\hline Incontinence & 3 & $3-15$ & $2.6(3.2)$ & 0.86 \\
\hline Patient care/support & 5 & $5-25$ & $6.6(5.5)$ & 0.83 \\
\hline Health system & 11 & Nov-54 & $18.4(2.8)$ & 0.91 \\
\hline \multicolumn{5}{|l|}{ ASE variables } \\
\hline Attitude & 6 & $-3 \pm 19$ & $3.9(4.2)$ & 0.58 \\
\hline \multicolumn{5}{|l|}{ Perceived Social support } \\
\hline -Physician & 1 & $\mathrm{NA}^{* *}$ & $0.3(1.4)$ & $\mathrm{NA}^{* *}$ \\
\hline -Partner/friend & 1 & $\mathrm{NA}^{* *}$ & $1.4(1.6)$ & $\mathrm{NA}^{* *}$ \\
\hline -Other persons & 1 & $\mathrm{NA}^{* *}$ & $-1.9(1.7)$ & $\mathrm{NA}^{* *}$ \\
\hline Efficacy & 3 & $3-15$ & $12.4(2.5)$ & 0.66 \\
\hline \multicolumn{5}{|l|}{ HADS } \\
\hline Anxiety & 7 & $00-12$ & $4.6(3.7)$ & 0.83 \\
\hline Depression & 7 & $00-16$ & $3.9(3.4)$ & 0.77 \\
\hline $\begin{array}{l}\text { Experience with psychosocial care interventions } \\
\text { (previous use of psychosocial interventions }+ \text { sum } \\
\text { score use specific professionals) }\end{array}$ & 2 & $0-20$ & $18.2(2.6)$ & $.61^{*}$ \\
\hline \multicolumn{5}{|l|}{ Evaluation ofreceived care } \\
\hline Evaluation care + support in general & 2 & $0-8$ & $12.3(3.1)$ & $.86^{*}$ \\
\hline supportive hospital care & 2 & $0-15$ & $9.4(2.8)$ & $.60^{*}$ \\
\hline $\begin{array}{l}\text { Behavioral intention (intention to seek supportive } \\
\text { care in the future }+ \text { looked for supportive care }+ \\
\text { sum score specific supportive care interventions) }\end{array}$ & 3 & $0-3$ & $1.2(1.2)$ & 0.8 \\
\hline
\end{tabular}

* inter-item correlations; ** NA: Not Applicable 
Table 2. Frequencies of socio-demographic and medical characteristics $(\mathrm{N}=87)$.

\begin{tabular}{|c|c|}
\hline Socio-demographic and medical characteristics & Percentage n (\%) \\
\hline Age (mean); range & 66.2 years; $44-84$ years \\
\hline Age $\leq 65$ & $39(44.8)$ \\
\hline Age $>65$ & $48(55.2)$ \\
\hline \multicolumn{2}{|l|}{ Marital status $(\mathrm{N}=\mathbf{8 6})$} \\
\hline Married and living apart together & $79(91.8)$ \\
\hline Presently no stable relationship (divorced, widower, single) & $7(8)$. \\
\hline \multicolumn{2}{|l|}{ Education } \\
\hline Primary education/primary vocational & $9(10.3)$ \\
\hline Secondary education, technical and vocational training & $35(40.2)$ \\
\hline College or university & $43(49.4)$ \\
\hline \multicolumn{2}{|l|}{ Employment status } \\
\hline Working & $17(19.5)$ \\
\hline Unable to work due to illness, & $7(8,0)$ \\
\hline Retired & $63(72,4)$ \\
\hline \multicolumn{2}{|l|}{ Professional status $(\mathbf{N}=\mathbf{8 5})$} \\
\hline Skilled work/craftsman & $9(10.3)$ \\
\hline Vocational trained/administrative worker & $34(39.1)$ \\
\hline Higher management, management and academic professionals & $42(48.3)$ \\
\hline \multicolumn{2}{|l|}{ Income status } \\
\hline$<2300$ euro & $14(161)$ \\
\hline $2300-4800$ euro & $53(60.9)$ \\
\hline$>4800$ euro & $20(23.0)$ \\
\hline \multicolumn{2}{|l|}{ Residential area } \\
\hline South west Netherlands & $40(46.0)$ \\
\hline Other parts of Netherlands & $47(54.0)$ \\
\hline \multicolumn{2}{|l|}{ Medical treatment } \\
\hline Surgery/Prostatectomy & $44(50,6)$ \\
\hline Radiation treatment (Internal/external) & $49(56,3)$ \\
\hline Hormonal therapy & $32(36,8)$ \\
\hline Watchful waiting & $16(18,4)$ \\
\hline Other & $7(7,7)$ \\
\hline \multicolumn{2}{|l|}{ Metastasis } \\
\hline Yes & $19(21.8)$ \\
\hline Unknown yet & $12(13.8)$ \\
\hline No & $56(64.4)$ \\
\hline \multicolumn{2}{|l|}{ Co morbidity } \\
\hline Yes & $37(42.5)$ \\
\hline No & $50(57.5)$ \\
\hline \multicolumn{2}{|l|}{ Other diseases } \\
\hline Arthritis and rheumatic problems & $6(6.9)$ \\
\hline Heart related and hypertension & $11(12,6)$ \\
\hline Intestinal problems & 3.(3.4) \\
\hline Lung and airway diseases & $2(2.3)$ \\
\hline Metabolism & $6(6.9)$ \\
\hline Neurological complaints & $9(10.3)$ \\
\hline Cancer, other types & $2(2.3)$ \\
\hline Other & $7(8.0)$ \\
\hline
\end{tabular}

care as negative because they are not part of their believes or they don't evaluate the belief as high. The perceived social support was not valued positively. Especially the perceived support for seeking help by the physician and other people was valued negatively by $52 \%$ and $80 \%$ of the respondents. Nearly all participants described their efficacy to seek support positively (Table 4).
Table 3. Supportive Care Needs survey (SCNS)

\begin{tabular}{|l|c|c|c|c|c|}
\hline & $\mathbf{0 ~ ( \% )}$ & $\mathbf{1}(\mathbf{\%})$ & $\mathbf{2 - 4}(\mathbf{\%})$ & Mean & SD \\
\hline Psychological needs* & $0(0)$ & $2(3,7)$ & $80(91,9)$ & 43 & 42,5 \\
\hline Healthcare system needs* & $0(0)$ & $6(7,2)$ & $77(88,2)$ & 42 & 29,1 \\
\hline Sexual needs* & $0(0)$ & $13(15,1)$ & $73(83,8)$ & 48 & 33,7 \\
\hline Care and support needs* & $0(0)$ & $16(18,4)$ & $70(80,3)$ & 31 & 27,4 \\
\hline Physical needs* & $0(0)$ & $16(18,8)$ & $69(78,9)$ & 29 & 24,5 \\
\hline Incontinence needs* & $0(0)$ & $41(48,2)$ & $44(49,5)$ & 22 & 27,1 \\
\hline
\end{tabular}

$* \mathrm{~N}$ varying between 82 and 87 due to missing values

Table 4. Attitude, perceived social support and efficacy ( $\mathrm{N}$ : between $84-87$ : missingvalues).

\begin{tabular}{|l|c|c|c|c|}
\hline & $<\mathbf{0}^{*}$ & $\mathbf{\%}$ & $>\mathbf{0}^{* *}$ & $\mathbf{\%}$ \\
\hline Attitude & 11 & 13 & 73 & 83 \\
\hline Support other & 80 & 94 & 5 & 3 \\
\hline Support partner & 36 & 42 & 50 & 57 \\
\hline Support physician & 52 & 72 & 24 & 27 \\
\hline Efficacy & 0 & 0 & 86 & 99 \\
\hline
\end{tabular}

$*<0$ : belief or evaluation not present or unimportant

$* *>0$ : belief or evaluation present or important

\section{Distress}

The applied cut-off scores are in line with the HADS syntax [38] and show that $12 \%$ of the participants experienced feelings of depression (score $>8$ ), and $17 \%$ suffered from anxiety $(>8)$.

\section{Former use of psychosocial care}

More than one third of the participants had some experience with psychosocial supportive care (36\%).Further, 32\% of the participants used some kind of supportive care offered by the general practitioner while $20 \%$ consulted their medical specialist and, less frequently, the oncology nurse. Half of the respondents indicate that they never visited a centre for psychosocial care.

\section{Satisfaction with supportive care}

Participants were mainly satisfied with the received supportive care, both from hospitals and other institutions (56\%) and rewarded the support as beneficial (52\%). More than $20 \%$ of the participants valued their support from the hospitals as unsatisfactory, marking the received support from the hospital with a mean score of 6,7 on a zero to ten scale.

\section{Intention to seek psychosocial support}

Nearly half of the men (47\%) looked for psychosocial support in general. Further, they looked for expert information (38\%), individual counseling (16\%), support by telephone (9\%), contact with fellow patients (9\%) or the prostate cancer society (9\%), and visiting a psychooncology center (3\%). On a constructed scale of 0 to 3 (Table 1) the mean behavior intention is $1.2(\mathrm{~N}=85 ; \mathrm{SD}=1.2)$; $0(44 \%), 1(12 \%), 2$ (27\%) and $3(17 \%)$.

\section{Determinants of the intention to seek supportive care}

Correlations between the intention to seek supportive care and all studied independent variables are presented in Table 5. A positive correlation means that a higher value on the independent variables results in an increasing intention to seek psychosocial care. The results show significant correlations with nearly all needs domains, 
Table 5. Correlations between behavioral intention to care use and all factors $(\mathrm{N}=84)$.

\begin{tabular}{|l|c|c|c|}
\hline \multicolumn{2}{|c|}{ Correlation } & \multicolumn{2}{c|}{ Correlation } \\
\hline Bge & $-0.26^{*}$ & Attitude & $.29^{*}$ \\
\hline Socio-economic status & 0.05 & Support physician & 0.07 \\
\hline Marital stats & -0.02 & Support others & 0.17 \\
\hline Region of residence & -0.16 & Support partner & 0.02 \\
\hline & & Efficacy & 0.03 \\
\hline Medical characteristics & & & \\
\hline Metastisis & 0.12 & Distress & \\
\hline Surgical therapy & 0.06 & Anxiety & $.32^{* *}$ \\
\hline Radiation therapy & -0.07 & Depression & \\
\hline Hormonal therapy & 0.02 & & $.38^{* *}$ \\
\hline Comorbidity & 0.19 & Experience & \\
\hline & & Former use of & \\
\hline Needs (SCNS) & & - psychosocialcare & $.45^{* *}$ \\
\hline Physical needs & $.45^{* *}$ & - psychosocial supportive & .22 \\
\hline Psychological needs & $.55^{* *}$ & & 0.19 \\
\hline Sexual needs & $.49^{* *}$ & & \\
\hline Incontinence needs & 0.18 & Satisfaction & \\
\hline Support and care needs & $.46^{* *}$ & Satisfaction hospital care & 0.22 \\
\hline Health system needs & $.45^{* *}$ & Satisfaction general care & \\
\hline Pearson cortacs & & \\
\hline
\end{tabular}

Pearson correlation coefficients * $\mathrm{p} \leq .05 * * \mathrm{p} \leq .01$

Table 6. Results of multiple regression analysis (Forwards-model).

\begin{tabular}{|l|c|c|c|c|c|c|}
\hline Independent variable & standardized B & t-test & sign & $\mathbf{R}$ & $\mathbf{R}^{\mathbf{2}}$ & $\mathbf{R}^{\mathbf{2}}$ change \\
\hline Psychological needs & 0.4 & 3.56 & 0 & 0.63 & 0.39 & 0.39 \\
\hline Physical needs & 0.23 & 2.15 & 0.04 & 0.67 & 0.44 & 0.05 \\
\hline Depression & 0.21 & 2.12 & 0.04 & 0.69 & 0.48 & 0.04 \\
\hline
\end{tabular}

except for needs concerning incontinence. Further, the intention to seek psychosocial care is significant correlated with the attitudinal component of the ASE-model as well as with lower age, higher distress, and experience with and negative evaluation of former psychosocial care interventions (Table 5).

\section{Multiple regression analysis}

Multiple regression analysis (Table 6) shows significant relations between the behavioral intention to psychosocial care use and the following independent variables: physical needs, psychological needs and depression $(\mathrm{p} \leq .05)$. This means that the best predictive independent factors for the intention to seek psychosocial support are the needs concerning physical and psychological support, and depression (Table 6).

A further test of the model assesses significance of pathways in the model (Figure 2). When considering the indirect pathways, the path from the jointly significant socio-demographic and medical characteristics (Nagelkerke $=0.07$ ), through the jointly significant SCNS variables (Nagelkerke $=0.62$ ) to behavioral intension is the strongest significant pathway $(\mathrm{p} \leq .05)$ in explaining behavioral intention. The next significant pathway $(\mathrm{p} \leq .05)$ is from the jointly significant variables for experience and evaluation of former used psychosocial care interventions (Nagelkerke $=0.30$ ) through attitude (Nagelkerke $=0.43$ ) to behavioral intention. The direct paths from the jointly significant socio-demographic and medical characteristics (Nagelkerke $=0.20$ ) and from the jointly significant variables for experience and evaluation of former used psychosocial care interventions (Nagelkerke $=0.37)$ to behavioral intention are also significant $(\mathrm{p} \leq .05)$ (Figure 2).

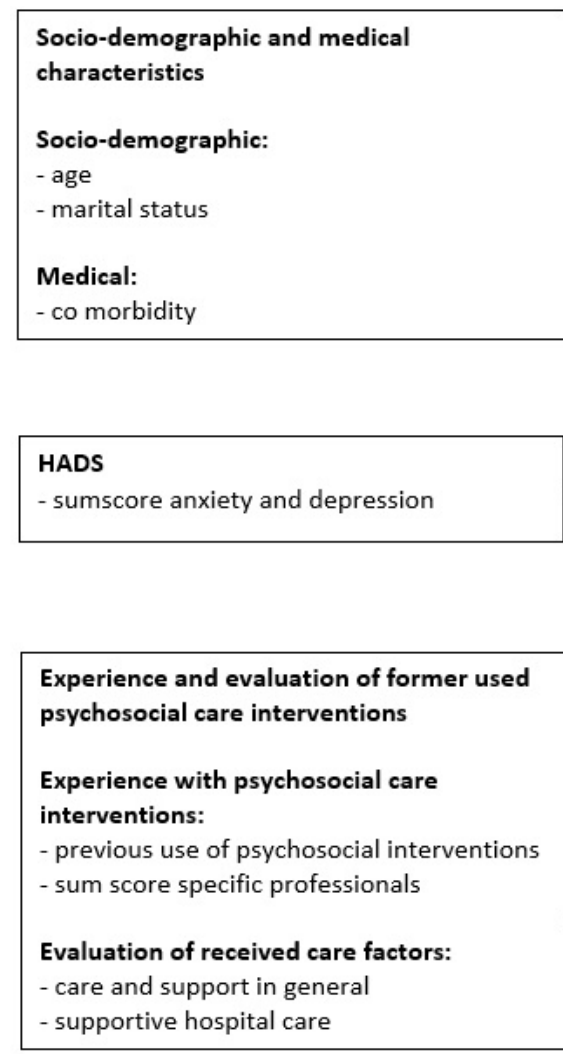

0.20

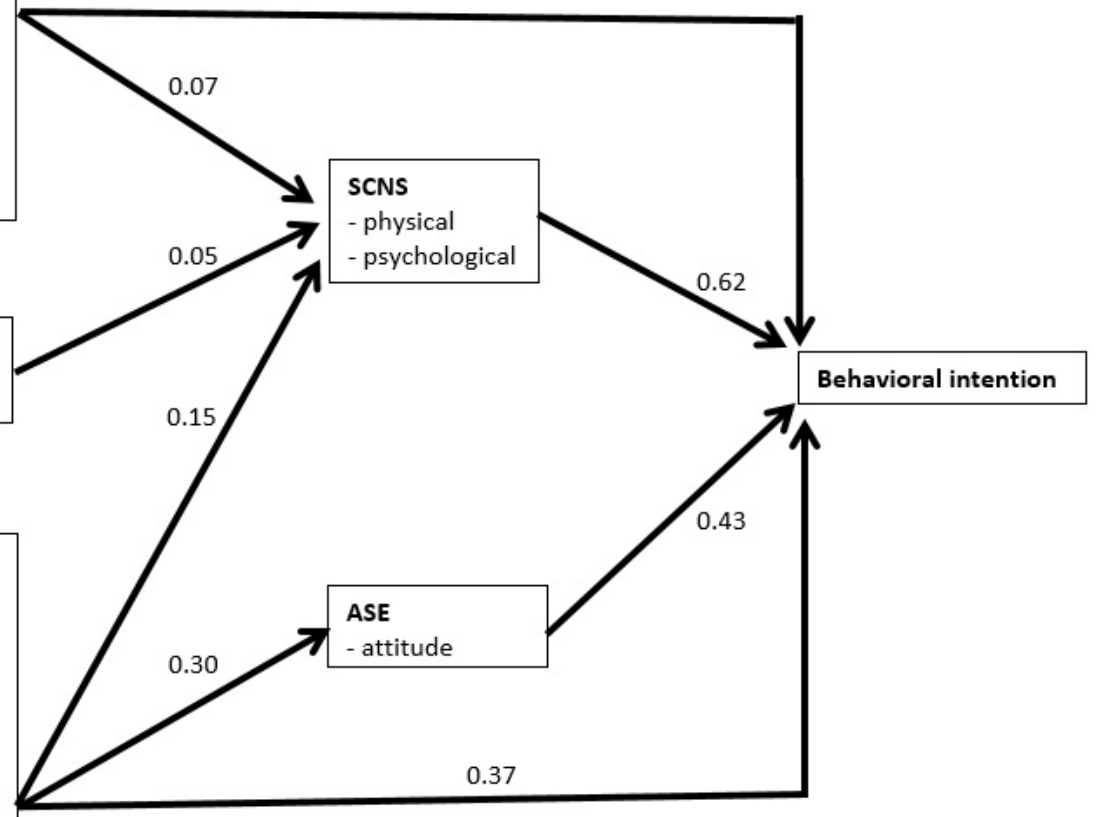

Pseudo R-Square Nagelkerke

Figure 2. The magnitude expressed in Pseudo R-square according to Nagelkerke of significant $(\mathrm{p} \leq .05)$ indirect and direct pathways in explaining behavioral intention. 


\section{Discussion}

Prostate cancer patients often express the need for supportive care, although they are not frequently participating in supportive care facilities. In a cross-sectional study we explored the factors that influence supportive care seeking of men with PCA. Beside patient's supportive care needs (SCNS) we applied the Attitude Social support Efficacy-model (ASE) whether their attitude about supportive care, perceived social support and self-efficacy do influence psychosocial care seeking. Further, the influence of distress, biographical and medical factors, previous experience with and evaluation of supportive care was studied. The determinants that influence the care-seeking intention are mainly psychological and physical needs, and depression.

Compared to previous studies that focussed on ASE-factors only, we used a mixed model, measuring needs as well as ASE-factors, and appropriate external factors. Patients' needs for support were assessed for the first time in a Dutch PCA-study. Needs are experienced by participants in all six life-domains. Especially needs concerning psychological, healthcare system, sexual and physical issues are present in the majority of the participants. Respondents are in need of supportive care and report answers ranging from having some needs to having urgent needs for support. There are no comparable data from other studies except the study by Voerman et al. [22] and Corboy et al. [23] applying also the ASE-model, but not measuring the needs. We found high scores on ASE-factors attitude and perceived selfefficacy, which aligns with the results of Voerman et al. and Corboy. Patients suffer less from depression than respondents in other studies. Low levels of depression, coincides with previous studies that showed moderate levels of psychopathology [18].

The SES of the studied men is higher compared to another Dutch study [14], however other general demographical features, such as age and disease related factors are in line with other Dutch samples [12-14]. Voerman et al. concluded that a higher SES is correlated with more interest in seeking care support, which could mean that also our higher SES respondents reported more interest in supportive care. However, that was not the case. An explanation is that differences in SES-scores may be of influence on the extent of coping with the PCA diagnosis. Voerman argued that more experienced distress relates to a worse adjustment to the cancer diagnosis [14]. Compared to our study it could mean that since our respondent's SES score is relatively high, they are better adjusted to the cancer diagnosis and therefore report fewer care needs.

The multivariate analysis show that the ASE-factors attitude, social support and efficacy do not modify supportive care seeking behavior, although previous studies by Corboy et al. and Voerman et al. indicated that using support interventions relate especially to attitudes towards psychosocial care and perceived efficacy $[22,23]$. Our results show a significant predictable value of psychological and physical needs and depression to the intention to use psychosocial care facilities. We also observed that needs are more important than attitude in relation to predicting care seeking behavior, as also found by Sanson-Fisher et al. [17]. The limited role of attitude in our study could be explained by the dominant role of the needs, which were not measured in former studies by Voerman et al. and Corboy et al. [22,23]. Our study confirms the coherence between ASE factors and needs. We found significant correlations $(\mathrm{p} \leq .05)$ between attitude and healthcare system needs $(\mathrm{r}$ $=0.27)$ and sexual needs $(r=0.28)$, which shows that a positive attitude and healthcare and sexual needs are mutually influencing factors. We also found significant correlations between support from others and the efficacy (0.33) and needs concerning incontinence $(r=-0.22)$. This indicates that men with high efficacy deal well with needs concerning incontinence due to the support by others. A final test of the applied theoretical model shows in the path-analysis that age, marital status and co-morbidity through physical and psychosocial needs to behavioral intention are the strongest factors explaining the intention to supportive care use.

The response on the participation requests was positive. All participants that contacted the investigator to receive the extensive questionnaire returned it. Further, we used several validated standardized measurement scales. A theoretical strength is that we combined the predictive value of the ASE-model and the needs measured by the Supportive Care Needs Survey (SCNS) model for the first time. We also measured various external factors according to the ASE model. The sample-size was small due to time limitations and also by difficulty in reaching the patient population via hospitals and healthcare professionals, who mentioned the high work-load at outpatient clinics and their own research activities as reasons for limited patient response to the announcements. Recruitment via the local psychosocial supportive care-center was difficult due to ethical arguments since it was not allowed to provide us with private client information. To evaluate the risk of selection bias due to limited sample size, we compared our sample with previous Dutch studies [12-14]. Comparison on disease related factors showed no sample differences. Our sample mainly compounds of respondents approached by the patient organization. From previous studies we know that patient organization members experience more distress [13,22,47]. Because our sample showed higher depression rates compared to anxiety, we may conclude that anxiety is not so much an issue for the respondents. In our study feelings of depression are of more influence on patient's search for support compared to anxiety.

\section{Conclusions}

The intention to seek care is mainly need related. Potential determinants that contribute to the intention to seek supportive are patient's attitude, sexual needs, support and care needs, health system needs, anxiety, age, previous psychosocial care use and satisfaction with former care. Most importantly however, factors that influence patient's intention to seek support are psychological and physical needs and depression.

The study contributes to a better understanding by healthcare professionals and organizations about patient needs and may stimulate the future development of fitting supportive care interventions. The results will substantiate patient referral to appropriate supportive care facilities by oncology/urology nurses. Our results provide useful information about specific influencing care seeking factors in PCA patients. Many patients experience problems concerning physical, psychological and social issues $[9,13,14]$. Nevertheless they don't attend supportive care much $[9,28,29]$. Given the important role of oncology nurses and other healthcare professionals in psychosocial support for PCA patients, the results may have practical implications for their daily practice and for further research. Previous research indicated that men look for expert information and programs that combine information and physical training rather than emotional support $[9,33,35]$. Healthcare organizations and professionals could use this information to further develop more needs and preference based interventions. Based on our study and previous research, interventions could comprehend clear expert information on psychological and physical issues $[9,13,18]$. 


\section{Acknowledgements}

We would like to thank the women who filled the questionnaire, the foundation the Vruchtenburg for their support, and Truus van der Hooft-Leemans, supervisor at the Leiden University, the Netherlands.

\section{References}

1. World Health Organization. Accessed November 2011. [www.who.org]

2. IKNL. Accessed October, 2011. [www.iknl.nl]

3. National Compass. Accessed October 2011. [www.nationalcompass.nl]

4. (2006)Muilekom HA, Spil JA. HandboekProstaatcarcinoom. Maarssen: Elsevier Gezondheidszorg.

5. McDowell ME, Occhipinti S, Ferguson M, Chambers SK (2011) Prospective predictors of psychosocial support service use after cancer. Psychooncology 20: 788-791. [Crossref]

6. Huang GJ, Sadetsky N, Penson DF (2010) Health related quality of life for men treated for localized prostate cancer with long-term followup. J Urol 183: 2206-2212. [Crossref]

7. Fowler FJ Jr, Barry MJ, Lu-Yao G, Wasson JH, Bin L (1996) Outcomes of externalbeam radiation therapy for prostate cancer: a study of Medicare beneficiaries in three surveillance, epidemiology, and end results areas. J Clin Oncol 14: 2258-2265. [Crossref]

8. Madalinska JB, Essink-Bot ML, de Koning HJ, Kirkels WJ, van der Maas PJ, et al. (2001) Health-related quality-of-life effects of radical prostatectomy and primary radiotherapy for screen-detected or clinically diagnosed localized prostate cancer. $J$ Clin Oncol 9: 1619-1628. [Crossref]

9. Voerman B, Fischer M, Visser A, AndelGv, Garssen B (2004) Prostate cancer: a review of the literature on psychosocial problems and psychosocial interventions. (Dutch) Gedrag en Gezondheid: Tijdschr Psychol Gezondh 32: 251-270.

10. Dale W, Bilir P, Han M, Meltzer D (2005) The role of anxiety in prostate carcinoma: a structured review of the literature. Cancer 104: 467-478. [Crossref]

11. Pirl WF, Siegel GI, Goode MJ, Smith MR (2002) Depression in men receiving androgen deprivation therapy for prostate cancer: a pilot study. Psychooncology 11: 518-523. [Crossref]

12. vanAndel G, Bottomley A, Fosså SD, Efficace F, Coens C, et al. (2008) An international field study of the EORTC QLQ-PR25: a questionnaire for assessing the health-related quality of life of patients with prostate cancer. Eur J Cancer 44: 2418-2424. [Crossref]

13. Visser A, van Andel G (2003) Psychosocial and educational aspects in prostate cancer patients. Patient Educ Couns 49: 203-206. [Crossref]

14. Voerman B, Visser A, Fischer M, Garssen B, AndelGv, et al. (2015) Symptoms of postraumatic stress and it's role in support care needs in men with prostate cancer. [To be submitted].

15. Korfage IJ, Essink-Bot ML, Janssens AC, Schröder FH, de Koning HJ (2006) Anxiety and depression after prostate cancer diagnosis and treatment: 5-year follow-up. $\mathrm{Br} \mathrm{J}$ Cancer 94: 1093-1098. [Crossref]

16. Bloch S, Love A, Macvean M, Duchesne G, Couper J, et al. (2007) Psychological adjustment of men with prostate cancer: a review of the literature. Biopsychosoc Med 1: 2. [Crossref]

17. Sanson-Fisher R, Girgis A, Boyes A, Bonevski B, Burton L, et al. (2000) The unmet supportive care needs of patients with cancer. Supportive Care Review Group. Cancer 88: 226-237. [Crossref]

18. Bisson JI, Chubb HL, Bennett S, Mason M, Jones D, et al. (2002) The prevalence and predictors of psychological distress in patients with early localized prostate cancer. BJU Int 90: 56-61. [Crossref]

19. Smith MY, Redd WH, Peyser C, Vogl D (1999) Post-traumatic stress disorder in cancer: a review. Psychooncology 8: 521-537. [Crossref]

20. Chambers SK, Pinnock C, Lepore SJ, Hughes S, O’Connell DL (2011)A systematic review of psychosocial interventions for men with prostate cancer and their partners. Patient Educ Couns 85: e75-88. [Crossref]

21. Hinz A, Krauss O, Hauss JP, Höckel M, Kortmann RD, et al. (2010) Anxiety and depression in cancer patients compared with the general population. Eur J Cancer Care (Engl) 19: 522-529. [Crossref]
22. Voerman B, Visser A, Fischer M, Garssen B, van Andel G, et al. (2007) Determinants of participation in social support groups for prostate cancer patients. Psychooncology 16: 1092-1099. [Crossref]

23. Corboy D, McLaren S, McDonald J (2011) Predictors of support service use by rural and regional men with cancer. Aust J Rural Health 19: 185-190. [Crossref]

24. Halbert CH, Wrenn G, Weathers B, Delmoor E, Ten Have T, et al. (2010) Sociocultura determinants of men's reactions to prostate cancer diagnosis. Psychooncology 19: 553560. [Crossref]

25. Helgason AR, Dickman PW, Adolfsson J, Steineck G (2001) Emotional isolation prevalence and the effect on well-being among 50-80-year-old prostate cancer patients Scand J Urol Nephrol 35: 97-101. [Crossref]

26. Carter N, Bryant-Lukosius D, DiCenso A, Blythe J, Neville AJ (2011) The supportive care needs of men with advanced prostate cancer. Oncol Nurs Forum 38: 189-198. [Crossref]

27. Gray RE, Fitch M, Phillips C, Labrecque M, Fergus K (2000) To tell or not to tell: patterns of disclosure among men with prostate cancer. Psychooncology 9: 273-282. [Crossref]

28. (2010) Annual report 2009 De Vruchtenburg. Rotterdam, the Netherlands.

29. (2010) Annual Report 2009 Helen Dowling Institute. Utrecht, the Netherlands.

30. Oliffe JL, Halpin M, Bottorff JL, Hislop TG, McKenzie M, et al. (2008) How prostate cancer support groups do and do not survive: British Columbian perspectives. Am J Mens Health 2: 143-155.[Crossref]

31. Helgeson VS, Lepore SJ, Eton DT (2006) Moderators of the benefits of psychoeducational interventions for men with prostate cancer. Health Psychol 25: 348-354. [Crossref]

32. Livingston PM, White VM, Hayman J, Maunsell E, Dunn SM, et al. (2010) The psychological impact of a specialist referral and telephone intervention on male cancer patients: a randomised controlled trial. Psychooncology 19: 617-625. [Crossref]

33. Berglund G, Petersson LM, Eriksson KC, Wallenius I, Roshanai A, et al. (2007) "Between Men": a psychosocial rehabilitation programme for men with prostate cancer. Acta Oncol 46: 83-89. [Crossref]

34. Lepore SJ, Helgeson VS, Eton DT, Schulz R (2003) Improving quality of life in men with prostate cancer: a randomized controlled trial of group education interventions. Health Psychol 22: 443-452. [Crossref]

35. Templeton H, Coates V (2004) Evaluation of an evidence-based education package for men with prostate cancer on hormonal manipulation therapy. Patient Educ Couns 55 : 55-61. [Crossref]

36. Tärnhuvud M, Wändel C, Willman A (2007) Nursing interventions to improve the health of men with prostate cancer undergoing radiotherapy: a review. Eur J Oncol Nurs 11: 328-339. [Crossref]

37. Walling AM, Maliski S, Bogorad A, Litwin MS (2004) Assessment of content completeness and accuracy of prostate cancer patient education materials. Patient Educ Couns 54: 337-343. [Crossref]

38. Polit D, Beck C (2008) Nursing research: Generating and assessing evidence for nursing practice. Philadelphia. Wolters-Kluwer Health.

39. (2009) Portney L, Watkins M. Foundations of Clinical Research. (3 $3^{\text {rd }}$ dn). New Jersey: Pearson Education International.

40. Boyes A, Hall A, Zucca A, Girgis A (2010) Supportive Care Needs Survey: supplement 2: reference data for cancer survivors 5-9 months post-diagnosis. The University of New Castle.

41. McElduff P, Boyes A, Zucca A, Girgis A (2004) Supportive Care Needs Survey: a guide to administration, scoring and analysis. New Castle. The University of New Castle.

42. Schoustra D, Visser AP (2012) The unmet psychosocial care needs in breast cance patients in the Netherlands. Report. University of Leiden. Rotterdam. De Vruchtenburg.

43. (2007) Pallant J. SPPS Survival Manual. New York. Open University Press.

44. Bjelland I, Dahl AA, Haug TT, Neckelmann D (2002) The validity of the Hospital Anxiety and Depression Scale. An updated literature review. J Psychosom Res 52: 69-77. [Crossref]

45. Segaar D, Bolman C, Willemsen MC, Vries H (2006) Determinants of adoption of cognitive behavioral interventions in a hospital setting: example of a minimal-contact 
Daeter L (2015) Communicating with prostate cancer patients: Psychosocial profile and determinants of seeking psychosocial care

smoking cessation intervention for cardiology wards. Patient Educ Couns 61: 262-271. [Crossref]

46. Hagoort K, van der Linden F (2007) Uurlonen per beroepsgroep; centrum voorbeleidsstatistiek. Centraal Bureau voor de Statistiek, Voorburg/ Heerlen.
47. Visser A, van Andel G (2003) Psychosocial and educational aspects in prostate cancer patients. Patient Educ Couns 49: 203-206. [Crossref]

48. Vocht A (2009) SPSS 16 voor Windows. (2 $2^{\text {nd }}$ edn). Utrecht: Bijleveld Press.

49. Field A (2013) Discovering statistics using IBM SPSS statistics.

Copyright: (C) 2015 Daeter L. This is an open-access article distributed under the terms of the Creative Commons Attribution License, which permits unrestricted use, distribution, and reproduction in any medium, provided the original author and source are credited. 